\title{
Evaluation of operational SSM/I ice-concentration algorithms
}

\author{
Walter N. Meier, ${ }^{1}$ Mighael L. Van Woert ${ }^{1,2}$ Cheryl Bertoia ${ }^{1}$ \\ ${ }^{1}$ U.S. National Ice Center, FOB \#4, Room 2301, 4251 Suitland Road, Washington, DC 20395, U.S.A. \\ ${ }^{2}$ NOAA/NESDIS Office of Research and Applications, Camp Springs, MD 20746, U.S.A.
}

\begin{abstract}
The United States National Ice Center (NIC) provides weekly ice analyses of the Arctic and Antarctic using information from ice reconnaissance, ship reports and high-resolution satellite imagery. In cloud-covered areas and regions lacking imagery, the higher-resolution sources are augmented by ice concentrations derived from Defense Meteorological Satellite Program (DMSP) Special Sensor Microwave/Imager (SSM/I) passive-microwave imagery. However, the SSM/I-derived ice concentrations are limited by low resolution and uncertainties in thin-ice regions. Ongoing research at NIC is attempting to improve the utility of these SSM/I products for operational sea-ice analyses. The refinements of operational algorithms may also aid future scientific studies. Here we discuss an evaluation of the standard operational ice-concentration algorithm, Cal/Val, with a possible alternative, a modified NASA Team algorithm. The modified algorithm compares favorably with Cal/Val and is a substantial improvement over the standard NASA Team algorithm in thin-ice regions that are of particular interest to operational activities.
\end{abstract}

\section{INTRODUCTION}

For the past 20 years, multichannel passive-microwave sensors have provided valuable information on the concentration and extent of the Arctic sea-ice cover. Passive-microwave imagery provides daily coverage of the entire basin, and in comparison to visible and infrared imagery is relatively insensitive to most clouds and atmospheric conditions.

The 20 year record encompasses the Scanning Multichannel Microwave Radiometer (SMMR) and the Special Sensor Microwave/Imager (SSM/I). Recent analysis of this relatively long satellite record has detected a downward trend in the ice concentration in the Arctic, possibly due to global warming (Johannessen and others, 1999; Parkinson and others, 1999; Vinnikov and others, 1999). Through feedback mechanisms, such changes in the ice cover could have substantial ramifications for climate, as well as operational activities in the Arctic.

Though sparsely populated, the Arctic is an area of importance for human activities. Submarines cruise the oceans under the ice cover (Gosset, 1996). Fishing and oil-drilling operations occur on the ice shelves. Indigenous peoples rely on marine and terrestrial wildlife (and their movements around, under and on the sea ice) in the region to provide sustenance.

The United States National Ice Center (NIC) supports these activities by providing weekly charts of ice conditions over the entire basin. The charts are based as much as possible on high-resolution satellite imagery (e.g. from RADARSAT, Defense Meteorological Satellite Program (DMSP) Operational Linescan System (OLS), Advanced Very High Resolution Radiometer (AVHRR) sensors), aircraft surveillance and, when available, ship observations. However, these sources have limited coverage or are frequently obscured by clouds. Therefore, the daily basin-wide coverage from SSM/I provides an important background component of the analyses.
In addition, the passive-microwave fields are used as initialization for the U.S. Navy's sea-ice forecast model, the Polar Ice Prediction System (PIPS) (Preller and Posey, 1989).

Several algorithms have been developed to derive iceconcentration fields from SSM/I brightness temperatures, primarily for observation of seasonal and interannual variations in the ice pack relevant to climate studies (e.g. Steffen and Maslanik, 1988; Steffen and Schweiger, 1991; Bjørgo and others, 1997; Cavalieri and others, 1997; Maslanik and others, 1999). Unfortunately, the ice concentration algorithms commonly used for scientific climate studies, such as the NASA Team algorithm, are inadequate for operational use because they underestimate thin-ice concentrations (generally ice $<10 \mathrm{~cm}$ thick) (Cavalieri, 1994). This is a significant drawback for operational purposes since extensive human activity (e.g. fishing) occurs in thin-ice regions such as the Bering and Chukchi Seas, the Barents Sea and the Sea of Okhotsk; they are also regions where the extent and character of the ice can change rapidly. Such errors in identifying thin-ice regions also compromise the effectiveness of the algorithms used in research studies (e.g. model comparisons).

Thus, the operational community has employed a different algorithm, the $\mathrm{Cal} / \mathrm{Val}$, which is optimized for regions particularly relevant to ice analyses (such as near the ice edge). However, it has limited application in the central ice pack because the algorithm saturates to $100 \%$ concentrations. To date, intercomparisons between these two algorithms (the NASA Team and Cal/Val) has been limited and there has been little effort to reconcile the results of the differing algorithms (e.g. Steffen and others, 1992; Partington, 2000).

Here we compare the NASA Team algorithm, the operational $\mathrm{Cal} / \mathrm{Val}$ algorithm and a new hybrid algorithm, the NIC Hybrid. The NIG Hybrid algorithm adjusts parameters to optimize the concentration retrievals, depending on conditions (marginal ice zone vs pack ice). This should 
increase the accuracy in regions of importance for the operational community, while retaining consistency with the accepted scientific algorithms.

\section{BACKGROUND}

The emissivity of sea ice and ocean varies primarily as a function of frequency, polarization and incidence angle (Eppler and others, 1992). Sea ice radiates more microwave energy than the surrounding water. Thus, satellite passive-microwave sensors can distinguish between ice and open water. Sea ice has radiative properties that vary as a function of ice age (due to changes in crystal size and shape, and the properties of brine channels) and thickness, salinity content and snow cover. This allows discrimination of different types of sea ice, such as first-year ice, multi-year ice and thin ice.

$\mathrm{SSM} / \mathrm{I}$ retrieves the surface brightness temperature, which is a function of the emissive properties of the surface and the physical temperature. It contains four frequency channels, 19, 37, 22 and $85 \mathrm{GHz}$. The $22 \mathrm{GHz}$ has a single polarization, while the others have dual, horizontal and vertical, polarization. Because of limited atmospheric interference, the 19 and $37 \mathrm{GHz}$ channels have been the primary frequencies used for ice-concentration retrievals, although $85 \mathrm{GHz}$ has been employed in some algorithms (e.g. Markus and Cavalieri, 2000). Figure 1 shows a plot of typical microwave signatures of open water, first-year ice and multi-year ice at the 19, 37 and $85 \mathrm{GHz} \mathrm{SSM} / \mathrm{I}$ channels.

\section{DESGRIPTION OF ALGORITHMS}

Several ice-concentration algorithms have been developed and evaluated for use with passive-microwave imagery (e.g. Steffen and others, 1992; Comiso, 1995; Comiso and others, 1997). Here we focus on three algorithms that are being used or have been considered for use operationally at NIC. Each is described below, including a discussion of their limitations.

\section{Cal/Val algorithm}

The Cal/Val algorithm (Hollinger and others, 1991) is the current operational standard and is used to initialize the PIPS sea-ice forecast model. It is a modified version of the AESYork algorithm (Ramseier and others, 1988). In the interior of the ice pack, the algorithm uses a linear combination of the vertically polarized 19 and $37 \mathrm{GHz}$ channels. Near the ice edge, only the vertically and horizontally polarized $37 \mathrm{GHz}$ channels are employed, unless weather effects (e.g. thick clouds, ocean roughening) are found to be important. A series of automated tests, using thresholds of brightnesstemperature combinations, is used to determine where these effects cannot be ignored. The use of a single channel at the ice edge has distinct advantages. The $37 \mathrm{GHz}$ channel has a smaller $(38 \mathrm{~km} \times 30 \mathrm{~km})$ footprint than the $19 \mathrm{GHz}$ channel $(70 \mathrm{~km} \times 45 \mathrm{~km})$. A previous study has shown that the use of only the $37 \mathrm{GHz}$ channel results in an ice edge 20-40 km poleward compared to the ice edge determined using both 19 and $37 \mathrm{GHz}$ frequencies (Partington, 2000).

The algorithm also uses a weather filter to eliminate spurious concentration retrievals and an additional check of pixels deemed ice-free via an oceanic parameters algorithm. This further improves performance at the ice edge.

The Cal/Val algorithm is also effective at capturing thinice areas (Partington, 2000). However, because it is designed

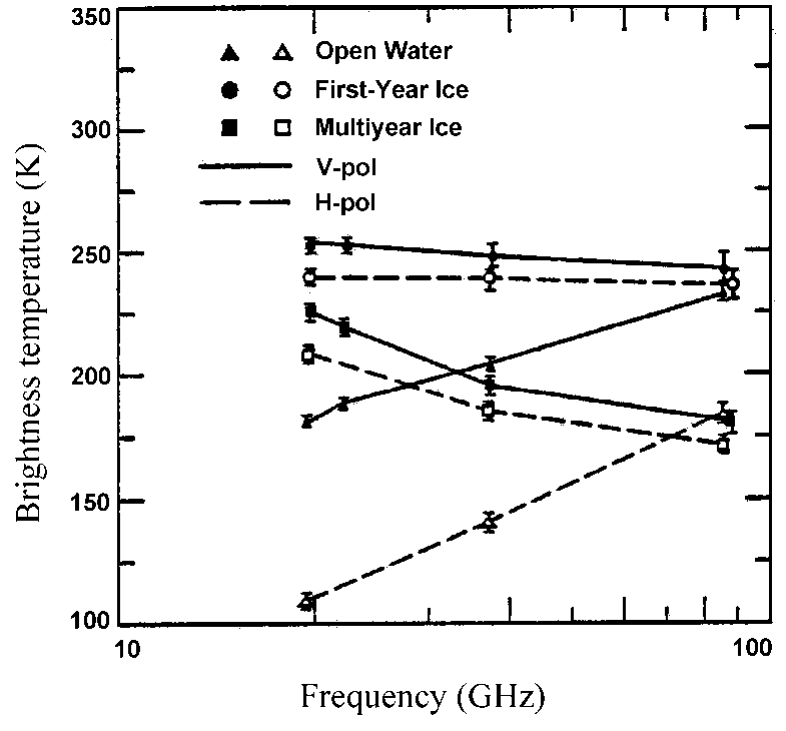

Fig. 1. Dependence of surface brightness temperature on surface type at SSM/I frequencies and polarization, observed on 17 January 1988 ( from Eppler and others, 1992).

to be particularly sensitive to the presence of ice, even thin ice, the algorithm consistently overestimates winter packice concentrations due to saturation, resulting in large regions where the concentrations are truncated to $100 \%$ ice cover. Thus, the Cal/Val algorithm lacks the ability to detect fine-scale concentration variations in regions of nearly complete ice cover; it may also be insensitive to small variations of concentration in regions of lower ice concentration as well, although this has not been investigated in detail.

\section{NASA Team algorithm}

The NASA Team algorithm, hereafter referred to as the NT algorithm, has been widely used by the scientific community for studies of the interannual variability of the ice pack (e.g. Parkinson and others, 1999), seasonal anomalies (e.g. Maslanik and others, 1999), trends in ice cover due to possible global change (e.g. Johanessen and others, 1999; Vinnikov and others, 1999) and for comparisons with modeled ice cover (e.g. Walsh and Zwally, 1990).

The algorithm is based on two radiance ratios, the polarization ratio (PR), given in Equation (1), and the gradient ratio (GR), given in Equation (2).

$$
\begin{aligned}
\mathrm{PR} & =\frac{T_{\mathrm{B}}[19 \mathrm{~V}]-T_{\mathrm{B}}[19 \mathrm{H}]}{T_{\mathrm{B}}[19 \mathrm{~V}]+T_{\mathrm{B}}[19 \mathrm{H}]} \\
\mathrm{GR} & =\frac{T_{\mathrm{B}}[37 \mathrm{~V}]-T_{\mathrm{B}}[19 \mathrm{~V}]}{T_{\mathrm{B}}[37 \mathrm{~V}]+T_{\mathrm{B}}[19 \mathrm{~V}]},
\end{aligned}
$$

where $T_{\mathrm{B}}$ is the brightness temperature for a given frequency $(19$ or $37 \mathrm{GHz}$ ) and polarization (horizontal, $\mathrm{H}$, or vertical, V).

These ratios are used as independent variables to solve for concentrations of open water, first-year ice and multi-year ice (Cavalieri and others, 1984). The use of ratios reduces the dependence of the retrievals on spatial and temporal variations of ice temperature. The algorithm uses tie points, based on brightness temperatures, to establish a reference of known pure surface classes (100\% water, 100\% first-year ice, 100\% multi-year ice). A weather filter, based on the GR ratio, is used as a cut-off to eliminate spurious ice retrievals over open ocean (Gloersen and Cavalieri, 1986). 
Because the algorithm uses both 19 and $37 \mathrm{GHz}$ channels in all areas, the ice edge is not resolved as accurately, compared to the Cal/Val algorithm. In addition, the NT algorithm has particular difficulty in regions of thin and new ice, as discussed above in the introduction.

\section{NIC Hybrid algorithm}

In November 1999, the Fleet Numerical Meteorological and Oceanographic Center (FNMOG) in Monterey, CA, began producing ice concentrations from a modified NTalgorithm as a secondary product for NIC, along with the operational $\mathrm{Cal} / \mathrm{Val}$ product. Like the Cal/Val and NTalgorithms, this product is designed for use throughout the Arctic region. In the Southern Hemisphere, FNMOC is producing ice concentrations from the Bootstrap algorithm (Comiso, 1986) as a secondary product. The Bootstrap product will be evaluated in comparison with the primary $\mathrm{Cal} / \mathrm{Val}$ product in a future study.

This modified NT routine, referred to here as the NIC Hybrid algorithm, uses the same basic methodology as the original, but contains two significant modifications to enhance performance for operational applications. First, it uses the Cal/Val output as an ice/no-ice binary mask. If the $\mathrm{Cal} /$ Val algorithm registers no ice in a given pixel, any ice appearing in that pixel in the NIC Hybrid output (due to ice detected within the larger footprint of the $19 \mathrm{GHz}$ channel, but outside the $37 \mathrm{GHz}$ channel's footprint) is eliminated. Thus, it has a more precise resolution of the ice edge (Partington, 2000).

It then uses a simple decision algorithm to determine where thin ice likely exists. If the gradient ratio, $\mathrm{GR}(37 \mathrm{~V})$ $19 \mathrm{~V}$ ) is greater than -0.015 for a given pixel, it is flagged as a possible thin-ice pixel. In these regions, the standard NT tie points are replaced with specialized thin-ice tie points based upon Cavalieri (1994). Table 1 gives the tie-point values for the standard NT and for the NIC Hybrid algorithm. If the concentration output using the NIC Hybrid tie points is less than the original concentration, then the original value is retained. The NIC Hybrid algorithm only replaces the original value if it results in increased concentration (i.e. thin ice that was missed by the original NT).

Other than the Cal/Val ice-edge mask, the NIC Hybrid is essentially a hybrid of the original NTalgorithm (producing partial concentrations of first-year and multi-year ice within the ice pack) and the NT Thin Ice algorithm (producing partial concentrations of thin/new ice and first-year ice in regions where thin ice predominates) of Cavalieri (1994). Therefore, over the Arctic domain, the NIC Hybrid algorithm can describe three distinct ice types: thin/new ice, first-year ice and multi-year ice. However, it can only retrieve two distinct ice categories (plus open water) for each individual pixel. Thus, pixels with mixes of multi-year, first-year and thin ice will result in errors.

Table 1. Multi-year ice tie-point values for the NT algorithm and replacement thin-ice tie-point values for the NIC Hybrid algorithm

SSM/I channel

$\mathcal{N T}$

NICHybrid

$\begin{array}{lll}19 \mathrm{H} & 203.9 \mathrm{~K} & 176.7 \mathrm{~K} \\ 19 \mathrm{~V} & 223.2 \mathrm{~K} & 235.6 \mathrm{~K} \\ 37 \mathrm{~V} & 186.3 \mathrm{~K} & 238.2 \mathrm{~K}\end{array}$

This hybrid approach is simple and computationally inexpensive and retains the ability to detect fine-scale variations in the pack, as in the NTalgorithm, while being optimized for detecting thin ice and more precisely observing the ice edge. Although the impetus for the development of the NIC Hybrid algorithm has been improved operational performance, it may potentially be beneficial to longer-term climate studies.

\section{RESULTS}

SSM/I-derived ice-concentration imagery using the Cal/ Val, NT and NIC Hybrid algorithms was collected from FNMOG for the period November 1999-January 2000. Here, we present results from 12 December 1999, with a focus on the Bering Sea region as a representative case for the study period.

\section{Comparison of Northern Hemisphere concentration}

Figure 2 shows the Northern Hemisphere sea-ice cover on 12 December 1999 from each of the algorithms. The NT algorithm indicates decreased ice concentrations, as low as $85 \%$, in thin-ice regions throughout the Arctic, such as the Bering, Barents, Kara and north Greenland Seas (as well as in some regions of thicker, multi-year ice, such as near the North Pole). Cal/Val indicates high concentrations (95-100\%) in these thin-ice regions near the ice edge, which is consistent with conditions observed by ice analysts in these regions (personal communication from J. Andrews, 2000). Notice also that the $\mathrm{Cal} / \mathrm{Val}$ algorithm saturates to $100 \%$ concentration and shows little variation within the central ice pack. The NIC Hybrid algorithm shows high ice concentrations, comparable to those from $\mathrm{Cal} / \mathrm{Val}$, in the thin-ice areas. Though not much difference is apparent between the NIC Hybrid and $\mathrm{Cal} / \mathrm{Val}$ outputs within the ice pack, the NIC Hybrid has less of a tendency to saturate, perhaps yielding more realistic spatial variability within the ice pack.

\section{Comparison of Bering Sea region}

A notable discrepancy exists in the Bering Sea, which is shown in greater detail in Figure 3. The NTalgorithm shows ice concentrations as low as $40 \%$ within the ice pack. A comparison with the NIC ice chart (Fig. 4) and visible AVHRR imagery (Fig. 5) for 13 December 1999 indicates ice concentrations of at least $80 \%$ in all regions except directly along the ice edge.

The NIC charts are based primarily on satellite imagery (from RADARSAT, AVHRR, OLS and occasionally SSM/ I) and the expertise of the ice analysts. The accuracy of the ice charts is governed by the subjective interpretation of imagery and other sea-ice information by the analysts. There are no statistics available to provide a quantitative assessment of the accuracy of the ice charts, and this is a limitation of the evaluation procedure. However, the ranges in the ice-chart concentrations reflect the range of uncertainty in ice concentration within a given region (Partington, 2000). Hence, an 80-100\% concentration indicated in the ice chart is analogous to a $90 \%$ concentration, with a $\pm 10 \%$ uncertainty. While the NIC charts are not ground truth and cannot provide an absolute reference with which to compare the SSM/I algorithms, they provide an unbiased source of ice-concentration information, independent (in this example) of SSM/ I. Thus, for a general assessment of the SSM/I products, the ice charts provide a reasonable baseline for comparison. 
a
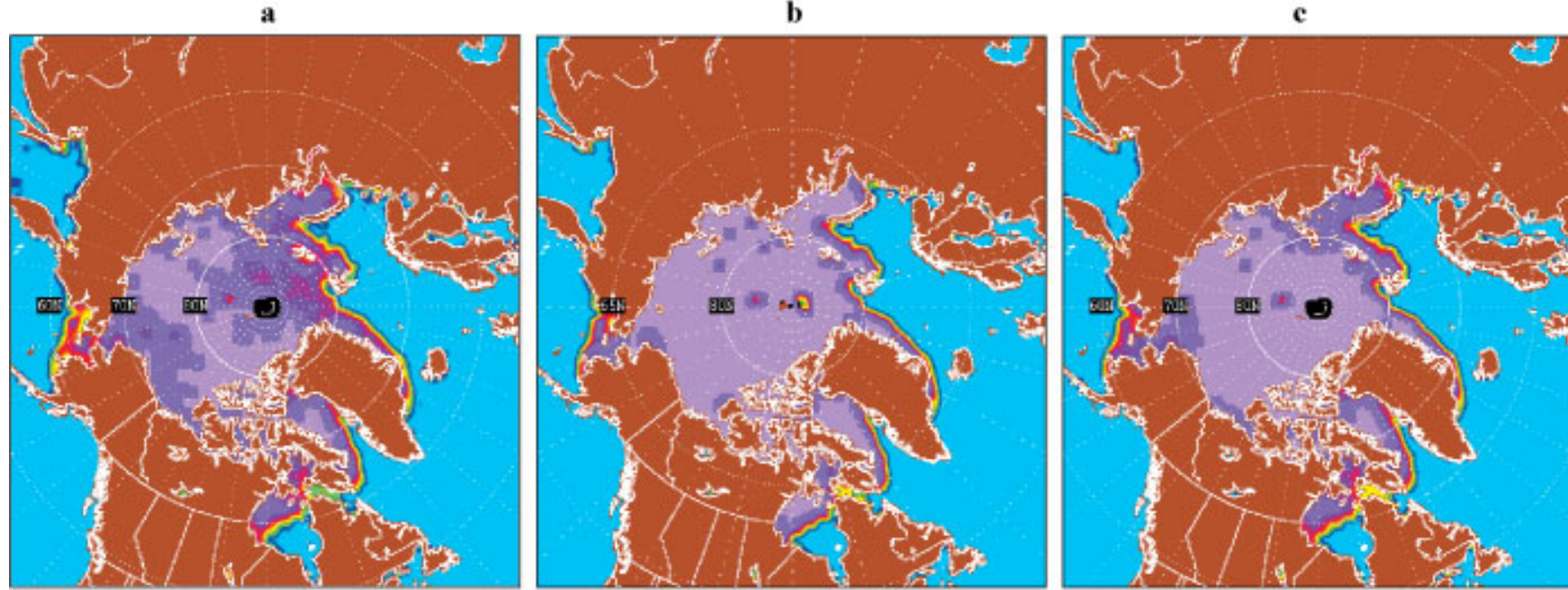

0
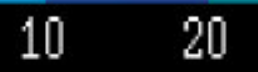

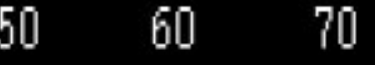

80
90

b

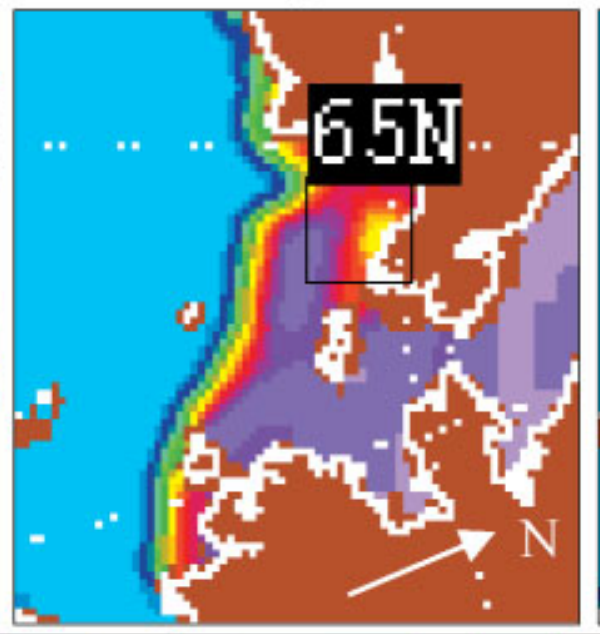

Fig. 2. Total ice concentration for 12 December 1999 in the Northern Hemisphere for (a) NT algorithm, (b) Cal/Val algorithm and (c) NIC Hybrid algorithm.

a

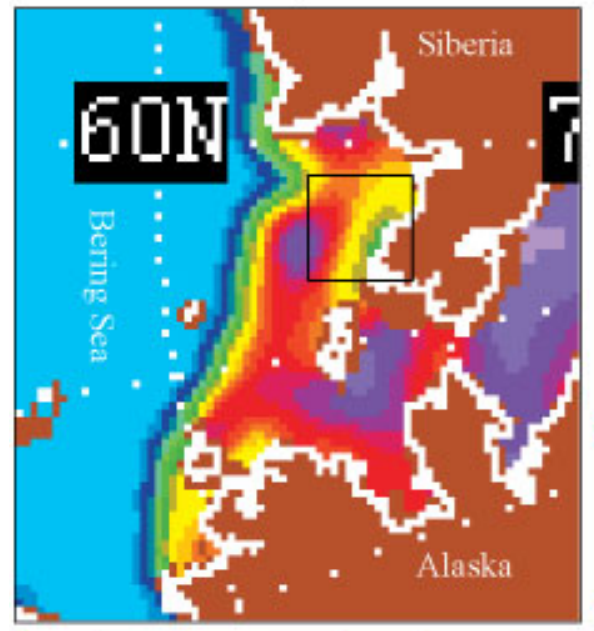

c

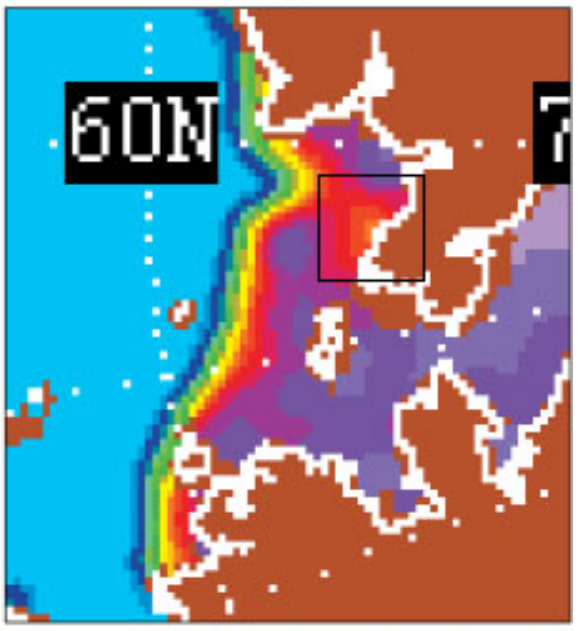

$90 \quad 100$

Fig. 3. Total ice concentration for the Bering/Chukchi Sea region on 12 December 1999 for (a) NTalgorithm, (b) Cal/Val algorithm and (c) NIC Hybrid algorithm. The box highlights a region of particularly large discrepancy between the three algorithms.

Although SSM/I is used as a supplemental source where higher-resolution imagery is unavailable, this NIC ice chart is based only on AVHRR and RADARSAT imagery. The boxed region of the ice chart in Figure 4, which is discussed further below, is based solely upon RADARSAT imagery. The example AVHRR image in Figure 5 is provided for a qualitative view of the general ice conditions over the entire Bering Sea region, and is not employed here for quantitative comparison.

The Cal/Val matches the ice chart reasonably well, showing $80-100 \%$ ice concentrations except near the ice edge. The NIC Hybrid concentrations match well with the $\mathrm{Cal} / \mathrm{Val}$ concentrations, again yielding concentrations generally of $80-100 \%$. One interesting feature, highlighted in the box in Figures 3-5, is a region directly south of the
Siberian coast in the western Bering Sea. Here the NT algorithm yields a concentration as low as 40\% (Fig. 3). The Cal/ Val algorithm indicates concentrations of only $50-60 \%$. These are both significantly different from the NIC chart, which shows concentrations of $90-100 \%$ (Fig. 4). The AVHRR imagery also shows possible decreased ice concentration (Fig. 5), but much of the area is likely covered by snow-free thin ice that appears darker than the surrounding ice. The NIC Hybrid algorithm, though also showing low concentration $(70-80 \%)$, is substantially closer to the ice chart than either the NTor Cal/Val algorithm.

Overall, the northern Bering Sea region has ice concentrations of $90-100 \%$, meaning there is $<10 \%$ open water throughout the region. However, the character of the ice is variable within the region. Examination of ice charts from 


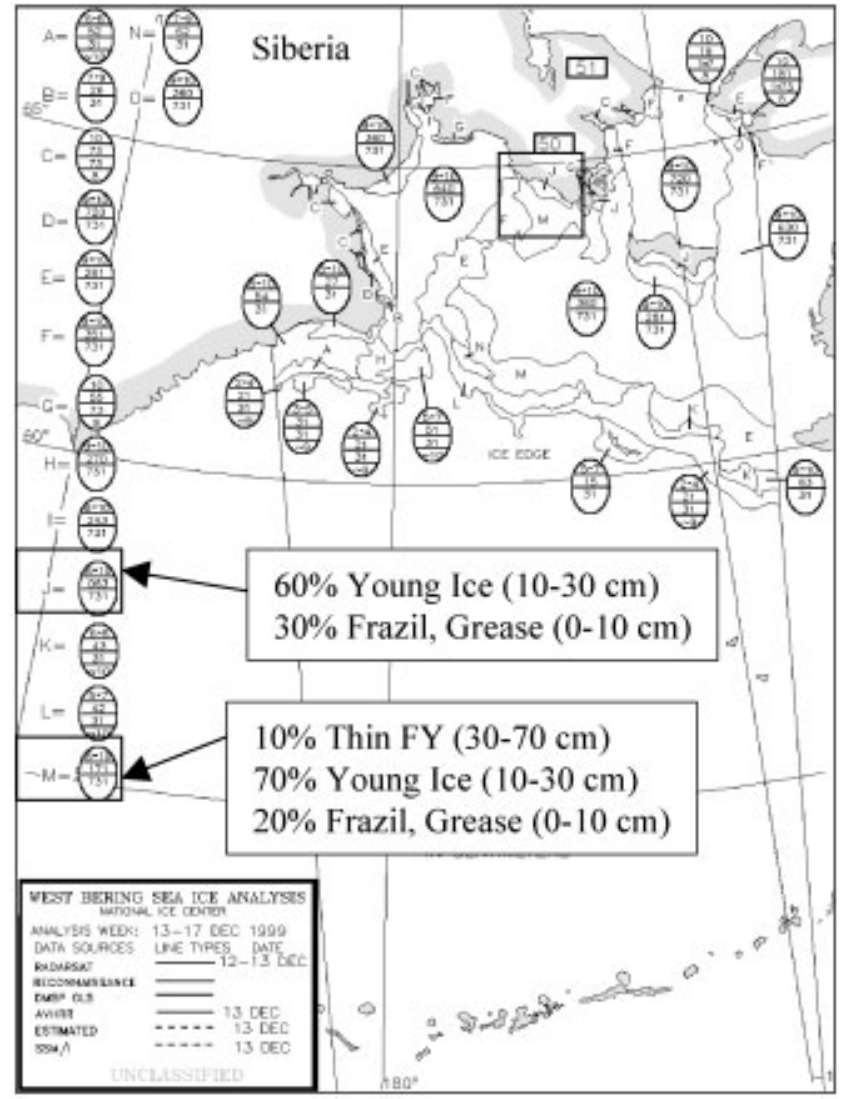

Fig. 4. Total ice concentration from NIC analyses for 13 December 1999 for the western Bering Sea region. The iceconcentration range for each sector is labeled in top line of "egg code" in tenths. The box south of Siberia corresponds to the boxes in Figure 3. The chart uses AVHRR, RADARSAT and OLS imagery as sources (solid lines); no SSM/I imagery (dashed lines) was used in this chart.

preceding days indicates that the boxed area started freezing up later than the surrounding regions. The region surrounding the boxed area consists almost entirely of thin first-year ice $(30-70 \mathrm{~cm}$ thick), and young ice $(10-30 \mathrm{~cm})$ frozen over the preceding several days. However, the boxed region contains a substantial amount $(30 \%$ of the total area) of very young frazil and grease ice (thinner than $10 \mathrm{~cm}$ ) that had just recently begun to freeze (according to the NIC ice chart, based on RADARSAT imagery).

While there is general agreement between the algorithms in regions where thin ice has undergone growth for a number of days, discrepancies are largest where the very thinnest and newest ice is present. These discrepancies occur even though all three algorithms employ the 19 and $37 \mathrm{GHz}$ channels, because the algorithms are optimized for different ice conditions. The NT algorithm uses tie points based on pack-ice conditions where ice has grown beyond the thin-ice stage. The Cal/Val algorithm is designed to be particularly sensitive to the presence of ice. Thus, Cal/Val is much more adept than NT at retrieving thin ice. The NIC Hybrid algorithm adjusts the hemispheric NT tie points to optimize retrievals in thin-ice regions. In this example, the NIC Hybrid algorithm is most accurate in these regions of newly formed thin ice. Thus, it appears that the NIC Hybrid algorithm can outperform the $\mathrm{Cal} / \mathrm{Val}$ algorithm where the thinnest and newest ice is present.

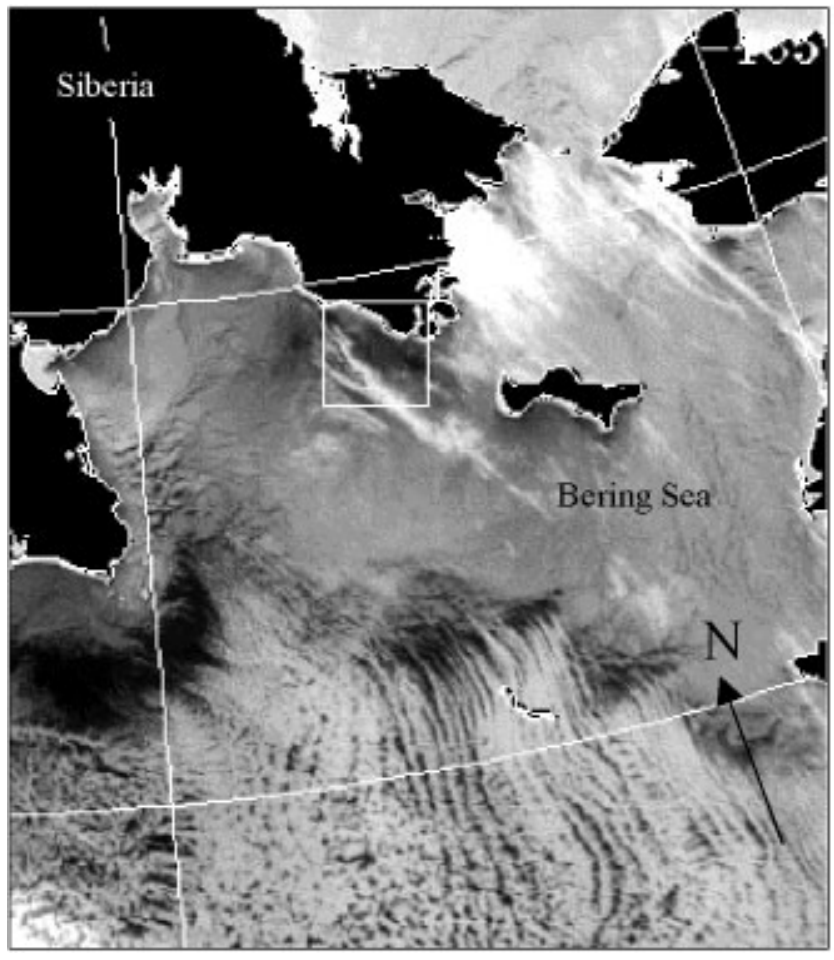

Fig. 5. Partially cloud-covered visible AVHRR imagery for western Bering Sea region on 12 December 1999. The ice edge is visible about 1/3 from bottom ( ocean is dark, covered by high clouds). The area of apparent reduced concentration and thin ice is noticeable just south of Siberia (darker color within box, corresponding to boxes in Figs 3 and 4).

\section{Ice-concentration difference maps}

To quantify the differences between the operational Cal/Val and the alternative NIC Hybrid algorithms, the 12 December 1999 NIC Hybrid concentrations are subtracted from the Cal/Val concentrations. Overall, the NIC Hybrid concentrations show good agreement over the whole Arctic, with differences generally within $\pm 10 \%$ (Fig. 6a); the best agreement occurs in the central Arctic, where concentrations are very close to $100 \%$. Even the larger discrepancies between the two algorithms in the Bering Sea are within $\pm 20 \%$ (Fig. 6 b). Note also the green shaded area in Figure $6 \mathrm{~b}$, corresponding to the boxed region discussed in the previous section, where the NIC Hybrid has higher concentrations than Cal/Val.

Raw data from the NTalgorithm were not available in a format comparable with the Cal/Val and NIC Hybrid products. Thus, a direct comparison with the NT algorithm concentration was not feasible. However, a similar study was conducted for the previous year (Partington, 2000), comparing NT with Cal/Val. Of course, there is considerable variability in the ice cover from one year to the next, thus making a direct comparison impossible. However, since the season is virtually the same, the difference between the two algorithms for 1999 should be comparable to the differences between the two for 1998. As expected, there is a considerable difference between the concentrations in the marginal ice zones, with the NTalgorithm underestimating concentration by as much as $30 \%$ compared to the $\mathrm{Cal} / \mathrm{Val}$ algorithm (Fig. 7). These differences for 1998 are consistent with the NTand Cal/Val products for the 12 December 1999 case studied here (Figs 2 and 3). 
a

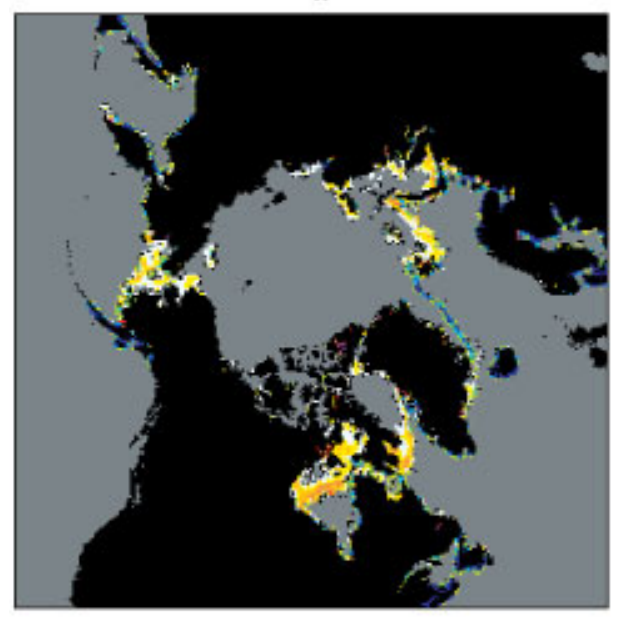

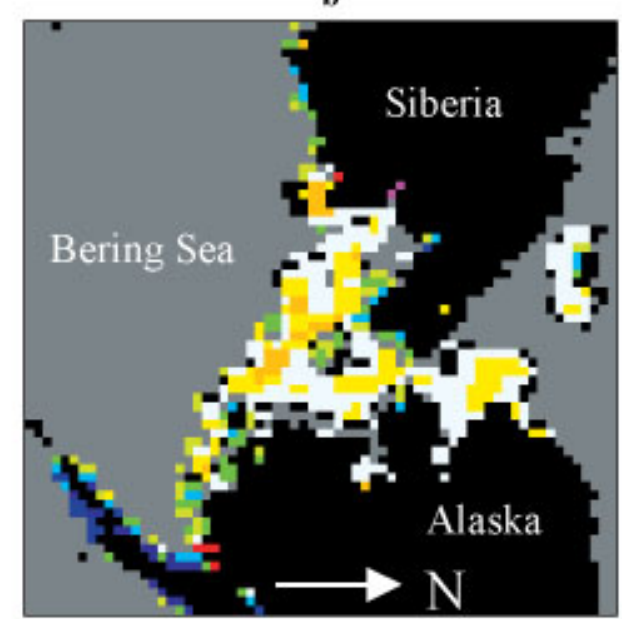

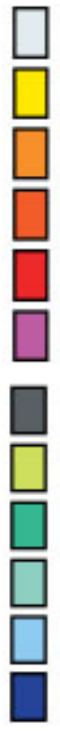

$$
\begin{aligned}
& +5 \text { to } 0 \% \\
& +10 \text { to }+5 \% \\
& +15 \text { to }+10 \% \\
& +20 \text { to }+15 \% \\
& +20 \text { to }+30 \% \\
& >+30 \% \\
& -5 \text { to } 0 \% \\
& -10 \text { to }-5 \% \\
& -15 \text { to }-10 \% \\
& -20 \text { to }-15 \% \\
& -20 \text { to }-30 \% \\
& <-30 \%
\end{aligned}
$$

Fig. 6. Difference between Cal/Val and NIC Hybrid concentrations (Cal/Val-NIC Hybrid) for 12 December 1999 for (a) Northern Hemisphere and (b) Bering/Chukchi Sea region.

\section{CONGLUSION}

This study indicates that the NIC Hybrid algorithm performs comparably to the $\mathrm{Cal} / \mathrm{Val}$ in regions of operational interest, particularly near the ice edge and in thin-ice regimes. Additionally, ice concentrations from the NIC Hybrid algorithm retain spatial variability in the central ice pack where the $\mathrm{Cal} / \mathrm{Val}$ algorithm tends to saturate to $100 \%$ ice concentrations. Thus, the NIC Hybrid appears to be more capable than $\mathrm{Cal} / \mathrm{Val}$ at detecting fine-scale spatial variations in regions of near $100 \%$ ice concentrations of thicker first-year and multiyear ice.

The NIC Hybrid algorithm appears to be a viable alternative to the $\mathrm{Cal} / \mathrm{Val}$ algorithm for operational purposes, although more data are required to quantify the performance of each algorithm. The NIC Hybrid also appears to be a useful algorithm for climate studies. These algorithms will be evalu- ated further, and other algorithms will be included in future studies. One promising algorithm is the NASA Team 2 (NT2) algorithm, which employs the $85 \mathrm{GHz}$ channel to improve concentration retrievals (Markus and Cavalieri, 2000). Although the $85 \mathrm{GHz}$ channel is very sensitive to atmospheric influence, the algorithm employs a simple atmospheric model to mitigate atmospheric effects. However, the algorithm may still be susceptible to difficulties in adverse weather conditions. The latest version of this algorithm includes refined tie points for optimal performance in thin-ice regions. Iceconcentration retrievals in the Antarctic will also be investigated, comparing the current operational Cal/Val algorithm with FNMOC's secondary product for the Southern Hemisphere, the Bootstrap algorithm (Comiso, 1986). Previous research has indicated that the Bootstrap algorithm is particularly well suited to Antarctic ice conditions and should perform favorably compared to the Cal/Val algorithm.

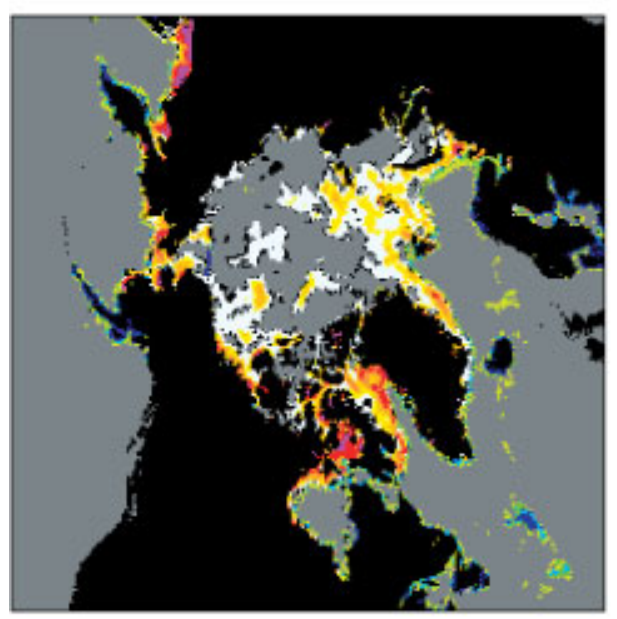

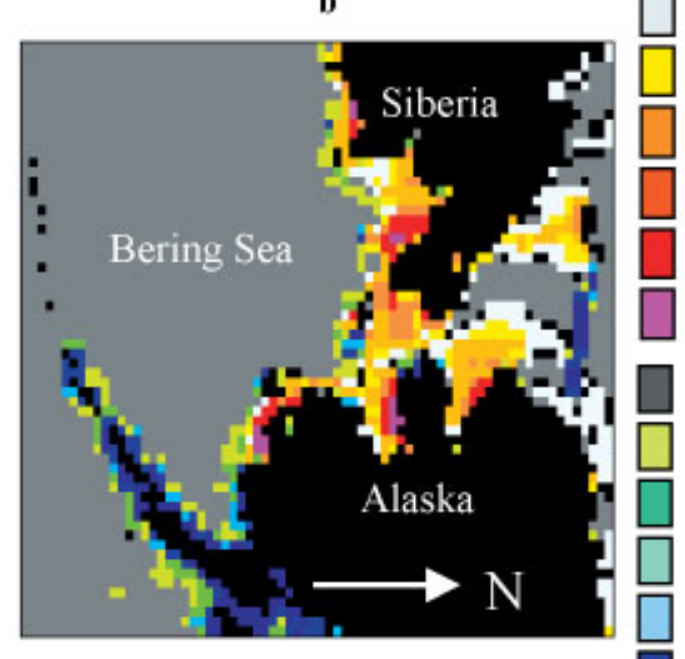

+5 to $0 \%$

+10 to $+5 \%$

+15 to $+10 \%$

+20 to $+15 \%$

+20 to $+30 \%$

$>+30 \%$

-5 to $0 \%$

-10 to $-5 \%$

-15 to $-10 \%$

-20 to $-15 \%$

-20 to $-30 \%$

$<-30 \%$ 
With the ongoing developments in ice-concentration algorithms for passive-microwave imagery and the increased resolution that will be available from future microwave sensors (e.g. the Advanced Microwave Scanning Radiometer), the utility of passive-microwave imagery for operational applications will be greatly increased. The ultimate goal is to eventually use passive-microwave imagery to provide automated global operational ice analyses. This would allow manual ice-charting efforts to be focused on regional and local tactical support.

\section{AGKNOWLEDGEMENTS}

This research has been supported in part by the University Corporation for Atmospheric Research Visiting Scientist Program and the NIC. Thanks to J. Haferman at FNMOC for some of the SSM/I imagery. NIC analysts collected the auxiliary imagery and some of the SSM/I imagery used in this study. Thanks to them, especially P. Seymour, M. R. Keller, C. Evanego, M. J. Shaffier and J. Andrews. Thanks also to N. Sandidge at U.S. Naval Research Laboratory, and S. Sertsu and E. Haas at NIC for assistance with the image analysis. Finally, thanks to the anonymous reviewers for their helpful comments.

\section{REFERENGES}

Bjørgo, E., O. M. Johannessen and M.W. Miles. 1997. Analysis of merged SSMR-SSMI time series of Arctic and Antarctic sea ice parameters 1978-1995. Geophys. Res. Lett., 24(4), 413-416.

Cavalieri, D. J. 1994. A microwave technique for mapping thin sea ice. $\mathcal{F}$. Geophys. Res., 99 (C6), 12,561-12,572.

Cavalieri, D. J., P. Gloersen and W. J. Campbell. 1984. Determination of sea ice parameters with the NIMBUS 7 SMMR. F. Geophys. Res., 89(D4), 5355-5369.

Cavalieri, D. J., P. Gloersen, C. L. Parkinson, J. C. Comiso and H. J. Zwally. 1997. Observed hemispheric asymmetry in global sea ice changes. Science, 278 (5340), 1104-1106.

Comiso, J. C. 1986. Characteristics of Arctic winter sea ice from satellite multispectral microwave observations. 7. Geophys. Res., 91 (Cl), 975-994.

Comiso, J. C. 1995. Satellite remote sensing of the Arctic Ocean and adjacent seas. In Smith, W. O. and J. M. Grebmeier, eds. Arctic oceanography: marginal ice zones and continental shelves. Washington, DC, American Geophysical Union, 1-50. (Coastal and Estuarine Series 49.)
Comiso, J. C., D. J. Cavalieri, C. L. Parkinson and P. Gloersen. 1997. Passive microwave algorithms for sea ice concentrations: a comparison of two techniques. Remote Sensing Environ., 60 (3), 357-384.

Eppler, D. T. and 14 others. 1992. Passive microwave signatures of sea ice. In Carsey, F. D. and 7 others, eds. Microwave remote sensing of sea ice. Washington, DC, American Geophysical Union, 47-71. (Geophysical Monograph Series 68.)

Gloersen, P. and D.J. Cavalieri. 1986. Reduction of weather effects in the calculation of sea ice concentration from microwave radiances. F. Geophys. Res., 91 (C3), 3913-3919.

Gossett, J. 1996. Arctic research using nuclear submarines. Sea Tech., 37(3), 33-40.

Hollinger, J., R. Lo, G. Poe, R. Savage and J. Pierce. 1987. Special Sensor Microwave/Imager calibration/validation. Washington, DC, U.S. Naval Research Laboratory. (Final Report.)

Johannessen, O. M., E.V. Shalina and M.W. Miles. 1999. Satellite evidence for an Arctic sea ice cover in transformation. Science, 286(5446), 1937-1939.

Markus, T. and D. J. Cavalieri. 2000. An enhanced NASA Team sea ice algorithm. IEEE Trans. Geosci. Remote Sensing, GE-38(3), 1387-1398.

Maslanik, J. A., M. C. Serreze and T. A. Agnew. 1999. On the record reduction in western Arctic sea-ice cover in 1998: characteristics and relationships to atmospheric circulation. Geophys. Res. Lett., 26(13), 1905-1908.

Parkinson, C. L., D. J. Cavalieri, P. Gloersen, H. J. Zwally and J. C. Comiso. 1999. Arctic sea ice extents, areas, and trends, 1978-1996. F. Geophys. Res., 104(C9), 20,837-20,856.

Partington, K. C. 2000. A data fusion algorithm for mapping sea-ice concentrations from Special Sensor Microwave/Imager data. IEEE Trans. Geosci. Remote Sensing, GE-38(4), 1947-1958.

Preller, R. and P. G. Posey. 1989. Polar ice prediction system - a sea ice forecasting system. NSTL Station, MS, Naval Ocean Research and Development Activity. (Final Report NORDA-212, in collaboration with Berkeley Research Associates, Springfield, VA.)

Ramseier, R. O., I. G. Rubinstein and A. F. Davies. 1988. Operational evaluation of Special Sensor Microwave/Imager. North York, Ont., York University. Centre for Research in Experimental Space Science. Atmospheric Environment Service.

Steffen, K. and J. A. Maslanik. 1988. Comparison of Nimbus 7 scanning multichannel microwave radiometer radiance and derived sea ice concentrations with Landsat imagery for the North Water area of Baffin Bay. 7. Geophys. Res., 93(C9), 10,769-10,781.

Steffen, K. and A. Schweiger. 1991. NASA team algorithm for sea ice concentration retrieval from Defense Meteorological Satellite Program special sensor microwave imager: comparison with Landsat satellite imagery. 7. Geophys. Res., 96 (C12), 21,971-21,987.

Steffen, K. and 6 others. 1992. The estimation of geophysical parameters using passive microwave algorithm. In Carsey, F. D. and 7 others, eds. Microwave remote sensing of sea ice. Washington, DC, American Geophysical Union, 201-231. (Geophysical Monograph Series 68.)

Vinnikov, K. Ya. and 8 others. 1999. Global warming and Northern Hemisphere sea ice extent. Science, 286(5446), 1934-1937.

Walsh, J. E. and H. J. Zwally. 1990. Multiyear sea ice in the Arctic: modeland satellite-derived. F. Geophys. Res., 95(C7), 11,613-11,628. 